\title{
An Evaluation Framework for Environmentally Sustainable Development of the Historic Cities within the Context of City Squares in Isfahan-Iran
}

\author{
Niloufar Vadiati ${ }^{1 *}$, Ali M. S. Kashkooli ${ }^{2}$ \\ ${ }^{1}$ Bartlett School of Planning, University College London, 22 Gordon Street, London, WC1H 0QB, United Kingdom, \\ Tel: +44-7955120461, E-mail: niloufar.vadiati@ gmail.com ,*corresponding author. \\ ${ }^{2}$ School of Architecture, The University of Sheffield, Arts Tower of Sheffield, Sheffield, S10 2TN, United Kingdom, \\ Tel.: +44-784-904-4635, Email address: alik188@ yahoo.com \\ doi:10.5618/arch.2012.v1.n2.5 || Received: 21-05-2012, Accepted: 08-07-2012, Available online: 23-07-2012
}

\begin{abstract}
The urban development involves more sensitive challenges for evaluation of the urban land use in respect of the framework of sustainable development. In the last three decades, the concept of sustainable development has developed into a broad area that embraces all methods and techniques in different levels of human activities and knowledge gaoling to save energy, time, financial and natural resources. Accordingly, environmental sustainability as a major aspect of the concept has concerned the environmental issues such as: climate change, global warming, waste management, sound masking, etc. The principal goal of this paper is to investigate the role of public squares in new urban developments in the historic cities from the perspective of environmental sustainability. Therefore, the paper considers some examples of the city squares in a case study (Isfahan-Iran) to highlight some problems in adaptation with the new $21^{\text {st }}$ century-style of urban development in such cities. Hence, the investigation compares the original historic squares vs. some recently developed ones. The literature review of this paper is based on the data gathered from internet, books and journals and previously published conference papers.
\end{abstract}

Moreover, a qualitative research has been conducted through local observation and survey in the location of the case study (Isfahan-Iran). The results will reveal the major principles of environmental sustainability in design of new public squares in such cities. This, in turn, opens new doors to future studies about adoption of old cities with new developments regarding to the concept of environmental sustainability.

Keywords: Environmental Sustainability, Public
Squares, Historic Cities, New Developments, Isfahan-Iran.

\section{Introduction}

In recent decades, the increase of population on the Earth has interested a remarkable attention to the 'Sustainability' concept. This has caused by the certain activities which has threaten the human well-being through the destruction of environmental integrity. Therefore, during the last two decades, many academic and governmental institutions have tried to define the meaning of sustainability and the indicators to measure it .For instants, the United Nations defined sustainability as a global process of development that minimises the consumption of environments resources. Moreover, it reduces the impacts on environment by using processes that simultaneously improve the economy and quality of life (UN World Commission on Environment and Development, 1987) [1]. Although Sustainability can be interpreted and measured differently in various level and contexts, in this paper it is defined as a term to fulfill "the needs of the present without compromising the ability of the future to meet its own needs" in a system [1].

Therefore, the concept has turned into a broad area embracing different levels of human activities and knowledge considering three major principles of: Environment, Economy, and Society (see Figure 1)

Hence, in the building and urban sector, it intends all levels of design and construction procedure in order to reduce the negative impacts of built environments on the eco-system (weather, land, water, energy, and resource consumption). Moreover, the concept aims to create reasonable but feasible economic systems with an ethical basis, as well as encouraging equitability and responsibility within the social and cultural systems [2]. 


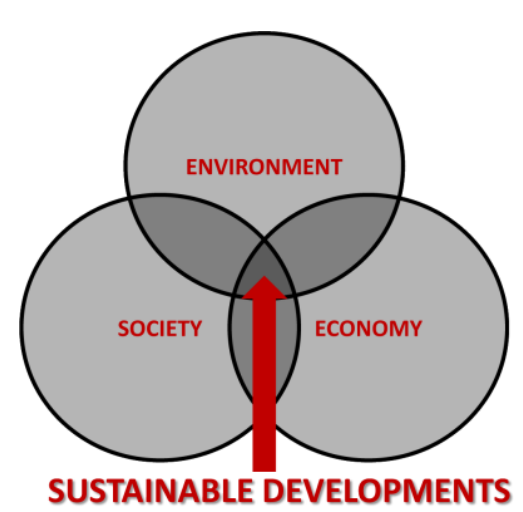

Fig. 1. The building blocks of sustainable development [2]

As formerly stated in the abstract, the principal aim of the paper is to explore the definition, typology and role of public squares in new developments and suburbia in historic cities. This investigation has been carried out focused on 'environmental sustainability' through some examples of historic and recently developed squares in Isfahan-Iran as a typical representative of the world historic cities. Therefore, some environmental problems caused by city adaptation with the new $21^{\text {st }}$ century-style of urban development would be high-lighted.

In a more critical view, environmental sustainability is established on the following aspects: conserving of the earth's vitality and diversity; conserving of life support systems; use renewable resources sustainably; minimizing the use of non-renewable resources; minimizing of pollution and damage to the environment and the health of living creatures; and conserving of the cultural and historical environment [2-3].

\subsection{Methodology}

1.1.1 Research Strategy: Introducing case studies. In order to study the public square, as a phenomenon, in Iranian context, the case study strategy is most appropriate. Isfahan is a traditional city and the second largest city in Iran, and has been chosen because the people of Isfahan have experienced many typologies of squares in the history of their city. However, as it is too time consuming to work on all public squares in Isfahan to examine the residents' social relationship with public squares and their desirable expectations, again we need to narrow down our case study and focus on two selected public squares. One (Naghsh-e-Jahan square) is selected from traditional squares, and another one (Enghelab Islami) is selected as a modern square.

\subsubsection{Research Method: Local resident} questionnaire. This research has been conducted established on a qualitative methodology including observations and survey in the case study location (Isfahan-Iran). The resident's questionnaire is the main contribution of this research work in terms of investigating the environment sustainability of squares for people according to their own views.

The questionnaire was undertaken to find out directly from some residents in Isfahan as representative of Iranian people about the main activity and the main function of two selected squares.

Since during the process of this research it was not feasible to go to Isfahan, the telephone Questionnaire was employed as a convenient and reliable mechanism. This research was undertaken based on the view of people from different social and economical backgrounds, and perspectives; however, the sampling was conducted in a 'semi quota sampling'(partly random and partly preconception selection) approach [4]. In addition, a 'snow-balling' technique [5] was used to find sufficient contacts. This means each participant led the research to some other contacts. For instance, if the first participant belongs to certain social class of Isfahan residents, most of the rest were being chosen from similar social class.

A population of 100 participants were selected through the aforementioned technique during the summer 2010. In each telephone interview, the set of questions about the environmental role of each square in the people's daily life was enquired in order to collect the qualitative data in depth.

Finally, both data sets were immerged together along with a critical regard to the previously gathered literature review; this provided synthesised findings. The synthesis was examined through the comparison of two case study squares from perspective of environmental sustainability.

\section{Urban public squares}

The public squares are the most intensively used urban spaces [6]. Fundamentally, squares are known as the places which present specific identity made by buildings, structures and their surrounding landscapes which define their form. These places can be of various shapes, sizes and functions. They often include trees and other landscapes. Crucially, they are the integral parts of the cities built form.

The American Heritage Dictionaries defines square as "an open, usually four sided area at the intersection of 
two or more streets, often granted with grass and trees for use as a park; or a rectangular space and close by streets occupied by buildings;"'[Reference]. Kevin Lynch [7] defines public square or plaza as "activity focus, at the heart of some intensive urban area. Typically, it will be paved, and closed to high density structure, and surrounded by street, or in contact with them. It contains features, meant to attract groups of people and to facilitate meeting [...]". Soltanzade in his book named as 'The Historic Studies About Iranian Open Spaces' defines the square as: "A Wide open space that has the enclosure or semi defined limitation and is located across the main roads or junctions. The function of square is connecting, social, commercial, sport, governmental army or mixed of some of them with each other [8].

Regarding to the scope of this paper, public square is defined as an open area surrounded by buildings and used for community gatherings and civic manifestation. From this perspective, many Iranian (Persian) contemporary squares can be considered. However, many of them are conducting another role as: connecting the urban areas (through transportation), trading zones, etc.

The developments of public squares in contemporary cities embrace many issues in urban design and urban regeneration. In a broader view, the achieved results and experiences of these developments can be applied to design of the other public spaces and built environments [9].

2.1 Typology of public squares in historic cities from environmental view. Typically, from environ- mental view public squares are being categorized in five types (see Figure 2):

- Closed squares: are characterised by complete enclosure which is broken only by those streets leading in to them. Uniformity and character of façades is also a determinate of closed square type. From environmental point of view, they are formally organised open spaces surrounded by buildings. This in turn, causes a suitable sun shine, and natural ventilation in with these squares.

- The dominate squares; which are being marked by directing towards one or a group of buildings. These squares are typically being directed to following buildings: church, palace, or town hall, as well as opening a view toward a mountain, river or open sea. These types of squares are mostly provided by good sound masking as closed public spaces with limited flow of traffic. They also are providing lots of sun shine for surrounding buildings in cloudy areas. Moreover, they provide more natural ventilation in comparison with the previous type.

- The Amorphous Squares: This category acts as a kind of catch-all for the previous categories. However, they do not signify any specific aesthetic and height-width ratio. Moreover, in comparison with the previous types they are performing the lowest sound masking, the highest sun shine, the highest flow of traffic, and therefore the lowest pedestrian satisfaction.

- $\quad$ The street Plazas: basically, this type is being furnished with green area and steps, seating place with ample sun shine in cloudy area and lots of shadow in dried and arid areas.

$\bullet$
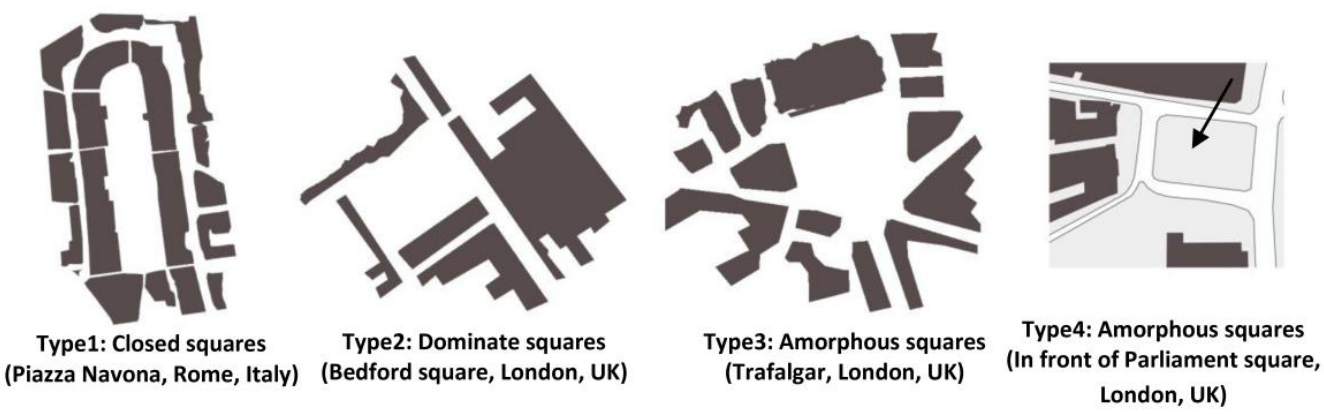

Fig. 2. Typology of public squares based on environmental view

\section{Case study}

Isfahan is "located about $340 \mathrm{~km}$ south of Tehran, and is the capital of Isfahan Province. After Tehran and

http://ccaasmag.org/ARCH
Mashhad it is Iran's third largest city" [10-11] (see Figure 3). In 2006 the city of Isfahan accommodated the population of $1,583,609$. The Isfahan metropolitan area also had a population of 3,430,353 in the 2006 
Census, which shows the second most populous metropolitan area in Iran after Tehran [12].

From historical perspective, the background of the city can be traced back to at least two millennia. The city was the capital of Iran (known as Persia at that time) for couple of times in 11-12th and 16-17th centuries. During that period of time, it became the most important city of the country. In the later periods, the city has been expanded enormously; and its original well-established urban structure has been complemented by the massive new urban developments [13].

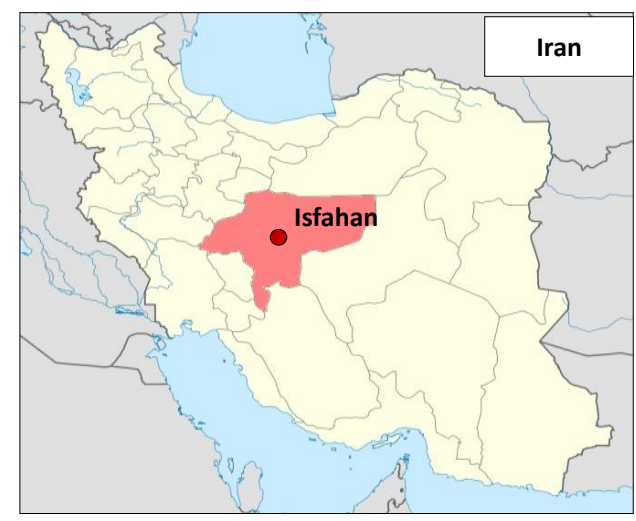

During its hundreds of evolution years, Isfahan has performed a good reputation in history of environmental activity in the world. This is because of the numerous street gardens and artificial streams branched from Zayandeh-rood River (the main city's river) from the old times; as well as the city's waste water management system developed in the latest fifty years. In the recent three decades, Isfahan has became a large, touristic-industrial city, which has inherited a huge legacy from the past. However, the city has been confronted with the problems caused by the clashes between the developments in the past and present [13].

Fig. 3. (a)Isfahan province in Iran, [14]

(b) Map of contemporary city of Isfahan, [14]

3.1 Naghsh-e Jahan Square. In this research, the Nagsh-e-Jahan square is being considered as an example of historic squares with a significant environmental design. Naghsh-e-Jahan (also called Imam Square) means World View Square and it is one of the biggest city squares in the world and an outstanding example of Iranian and Islamic architecture [15]. It has been designated by UNESCO as a World Heritage Site [16]. This extraordinary square was an enormous 510 by 165 meters rectangle enclosed by rows of shops and four magnificent monuments (Figure 4a and 4b) [16]. It was surrounded by "the royal palace, the central mosque, the main bazaar entrance, the music pavilion and religious schools" [15].

The former function of this square used to be commercial, governmental-recreational, social and athletic, e.g. playing polo [17]. At present, by specification of the most parts of the square to pedestrians its original function has been revitalised in a new style.

3.2 Enghelab Square. The second example considered by this research is the Enghelab Square. It has been developed during the last 80 years by the major programmes of constructing the highways and new urban developments in Isfahan. The square is located in the old and historic part of Isfahan (Figure 5) next to the $\mathrm{Si}$-o-Sepol (one of the famous historical bridges). Although it is next to the Siy-o-sepol bridge and near the Zayandeh Rood (Isfahan river) bank as popular attractions its main function is considered to is to run the traffic flow. 

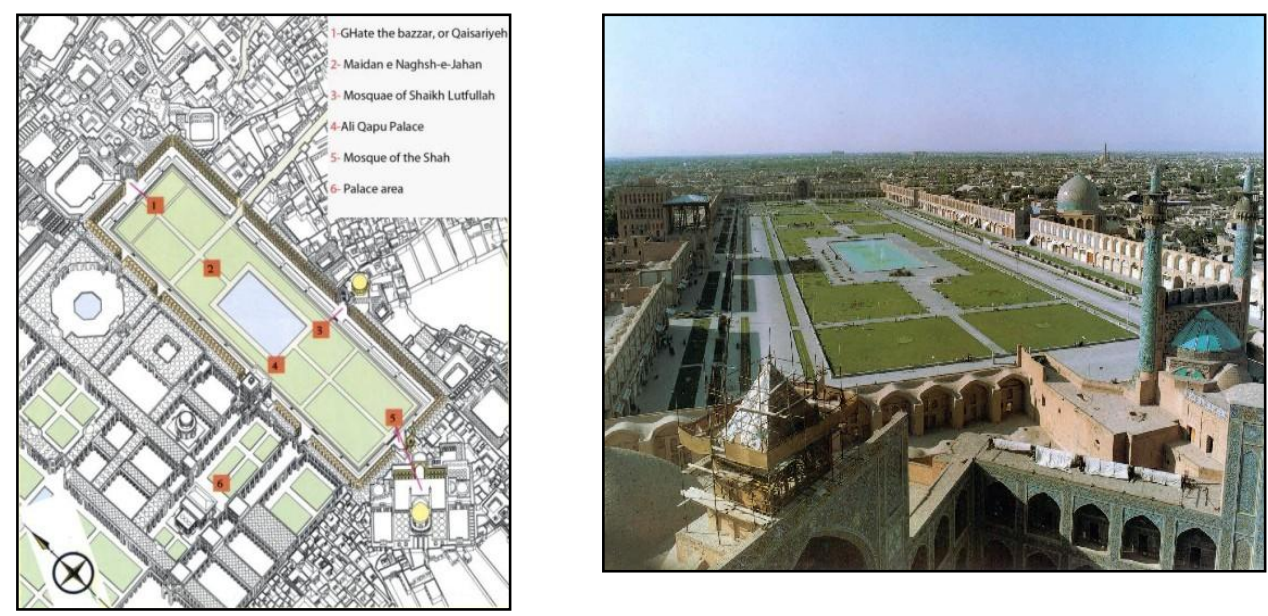

Fig. 4. (a)The plan of Naghsh-e-Iahan square, Isfahan, Iran [18] (b) Bird view of Neghsh-e-Jahan square

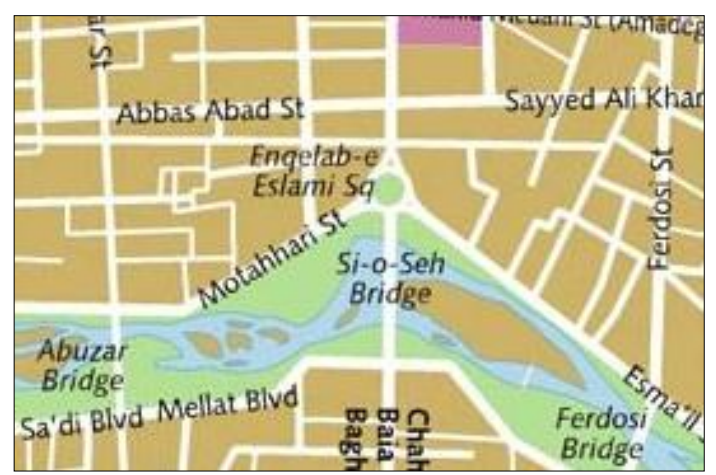

Fig. 5. (a)The plan of Enghelab square, Isfahan, Iran[19]

\section{Discussion}

4.1 Case study observation findings. The observation of both squares was carried out through series of photos taken in the following days of the summer 2010: Thursday morning, Thursday evening, and Friday morning (holiday in Iranian calendar). Accordingly, the following points were detected regarding the people's behaviours:

4.1.1 Enghelab square. The accumulation of cars, people and contradictory activities in the space of the square has caused intense conflict between cars and pedestrians. Moreover, the green landscape area in the centre of the square is not designated for pedestrian access.

Primarily, there are two general functions designated for Enghelab square as: connecting role, and commercial role. Presumably, it is one of the important junctions between Chaharbagh-e-Abbasi Street, Esmaeili Street

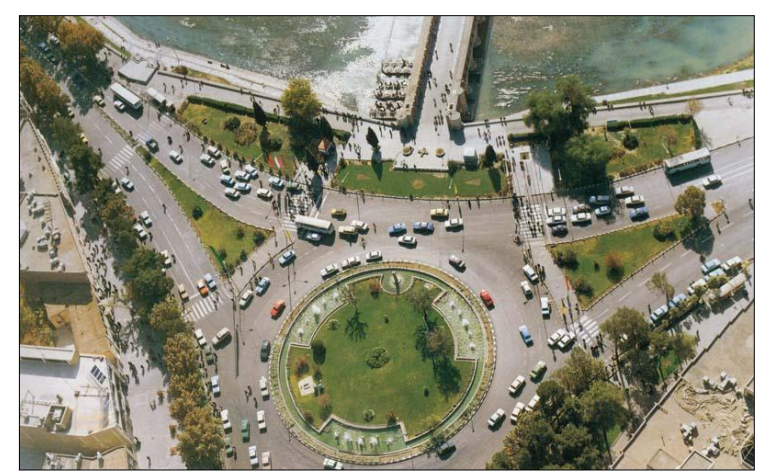

(b) Bird view of Enghelab square, Isfahan, Iran [20].

and Motahari Street, as the three old and main streets, constructed during first modern development in Isfahan. Thus, there is a significant load of traffic in the square during peak hours of day. This in turn causes high pollution considerable air pollution in the area.

Moreover, the placement of the square is in a way to benefit from the river in the neighbour (Zayandeh-Rood) in terms of sound masking and impacting on the air temperature. (Appendix A, Figures A1, A2). However, the low rate of green landscapes around the square (in comparison with high flow of traffic has reduced the mentioned impact of the river by increasing noise and air pollutions. In other words, the new development of the square is not matched with the flow of urban movements (e.g. shopping, commercial activities etc.).

From sun orientation view, the square have been designed in a reasonable approach in terms of positioning the surrounded buildings to attract the 
highest rate of solar energy in winters and lowest solar heat in summers.

4.1.2 NaghSh-e- Jahan Square. This square is actually pedestrianised public space with a limited vehicle access only in the west side of the square. Height and width ratio and arcades around squares provide a suitable shadow during the day, which is made by surrounded building and arcades. In addition, hand-on water features and green planted area in the centre is being used by pedestrians (Appendix A, Figure A3 and A4).

Most of the time, this traffic path copes with a narrow space and the congestion of cars which try to pass through these preserved spaces. Although, as it has formerly been stated that the height and width ratio and arcades around the square improves the quality of

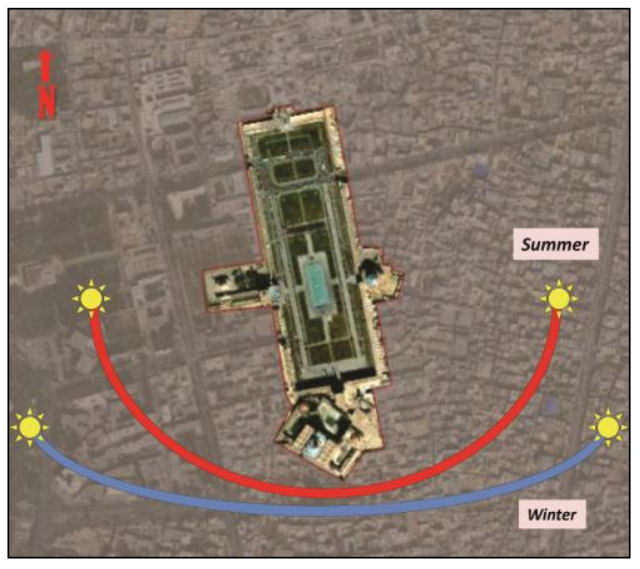

Fig. 6. (a) Solar orientation in Naghsh-e-Jahan square, (b)Solar orientation in Enghelab Square.

\subsection{Resident Questionnaire Findings}

\subsubsection{Traffic as a source of energy waste and carbon} emissions. In this theme, people were asked to choose as many activities as they think they usually do in both case studies: this action has been conducted to high light the efficiency of mentioned squares in terms of energy, carbon emissions and waste of natural resources (as some significant causes of global warming). The main considered task in this issue has been 'traffic'.

According to their feedback (see Figure 7), 45 percent (out of 100 interviewees) in Naghsh-e-Jahan square usually gather with their family and friends for entertainment and relaxing. Another activity which was selected by 42 percent was shopping.

Meanwhile, just 10 percent declared that they usually choose the Enghelab square to meet friends and undertake collective entertainment which is mostly shopping in passages and malls. Furthermore, 32 percent selected the shopping option as the most usual activity natural ventilation in the space. However, yet the hot and arid location of the city is forcing the people to leave the space during the hot daily hours.

Moreover, the water features in with the central open space are improving the environmental quality of the space by masking the noise and reducing the temperature.

From sun orientation view, Naghsh-e-Jahan Square designed in a way to attract the highest rate of solar energy during cold season and lowest attraction in the hot season. Moreover, the height of the buildings (approximately 20 meters) around square are matched to provide the highest rate of shadow during summer and hot seasons (see Figure 6a).

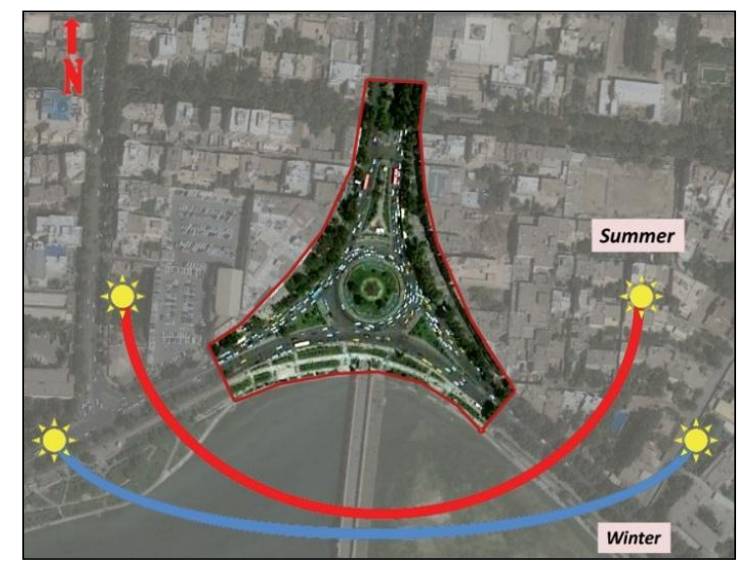

in Enghelab square; and the 27 percent said that they use Enghelab square as a connecting node to reach other street (see Figure 7).

4.2.2 Acoustic comfort of the squares. At this phase, to examine the impact of noise pollution in the case study squares, a general survey has been conducted through the local residents. Hence, the results have been as follows (see Figure 8):

76 percent (out of 100 interviewees) chose noise of cars in Enghelab square; 10 percent have heard the crowded of people; 14 percent have heard not specified sound, and nobody has heard the so und of river.

On the other hand, the result of survey in Naghshe Jahan square has been as follows: $48 \%$ have chosen carriage (a fantasy vehicle for movement of tourists around the square), 20\% have chosen swallower's sound, and a 3 percent have chosen noise of traffic. 
This confirms the success of Naghsh-e-Jahan square in terms of acoustic quality, which is provided by better organization of buildings, landscape and traffic.

To summarise, the Enghelab square, as the new developed square in Isfahan, is challenging with the following problems and conflictions:

- The confliction between accumulated cars in the existing flow of traffic;

- The clash of pedestrians and cars which can cause heavier traffics and noise pollution.
As the comparisons in this paper revealed, the most significant problems are 'traffic' and 'noise pollutions', which call for serious considerations to address these problems in the future.

In contrast, the well-designed organisation of spaces in Naghsh-e-Jahan square has made it capable to invite many people from different social classes to use the space for different purposes. Moreover, it offers suitable urban natural ventilation, acoustic comfort and energy efficiency to its surrounded buildings.

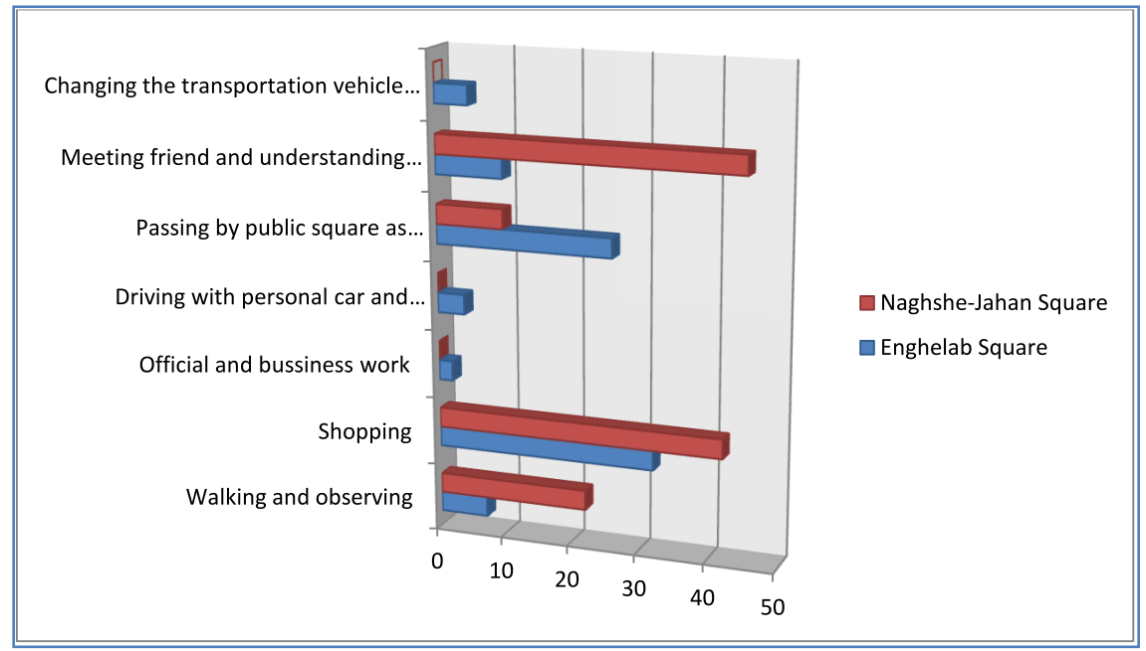

Fig. 7. Comparison of usual activities of people in two squares of the case study.
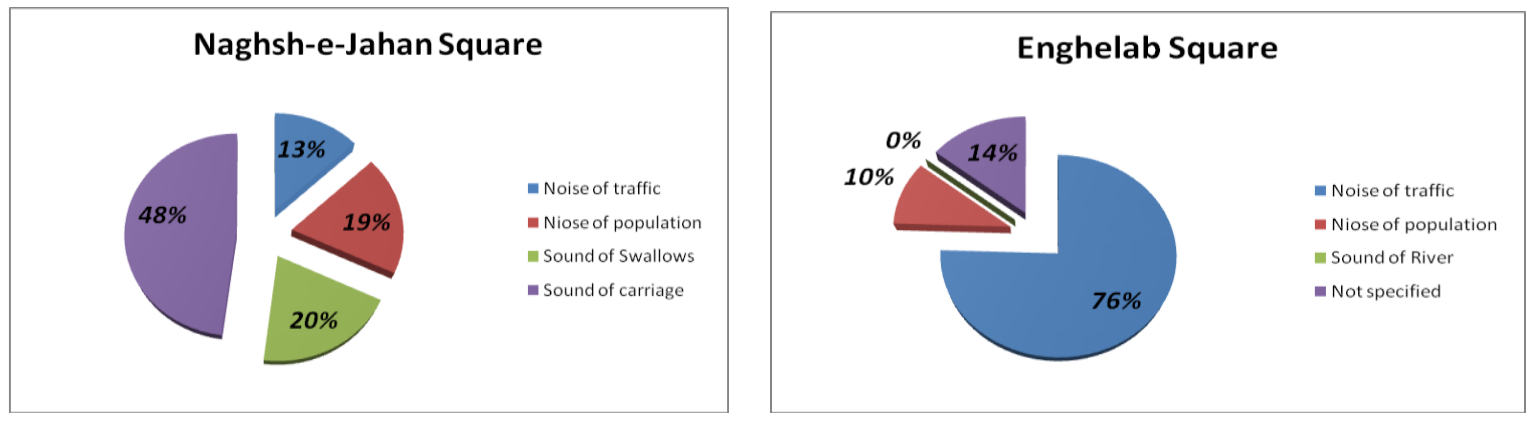

Fig. 8. (a) Comparison of residents feedback about acoustic comfort in Naghsh-e-Jahan Square, (b) Comparison of residents feedback about acoustic comfort in Enghelab Square. 


\section{Conclusion}

In conclusion, in new development of urban squares in historic cities the following environmental issues must be considered:

- The Sun orientation,

- The management strategy to design reasonable flows of traffic (regarding to potential grows of population, technologies and local transport systems),

- The green landscape and water features, which perform an appropriate acoustic comfort and urban thermal behaviours.

This paper opened new doors to further studies in the subjects relevant to sophistication and reasonability of designing new public squares in new developed urban areas and suburbia.

\section{References}

[1] G. H. Brundtland, "Brundtland Report : Our Common Future," Oxford, United Kingdom 1987.

[2] R. J. Lawrence, Sustaining Human Settlement: A Challenge for the New Millennium: Urban International Press, United Kingdom, 2000.

[3] A. M. S. Kashkooli, et al., "Employing Renewable Energy in Buildings and Urban Areas: Case of Off-Grid City 2009, South Korea," in Proceeding of 10th International Conference on Clean Energy (ICCE-2010), Famagusta, N. Cyprus, 2010.

[4] J. s. Biggam, Succeeding With your Master's Dissertation: Berkshire:McGrawhillHill, Open University Pre, 2008.

[5] L. A. Goodman, "Snowball sampling," Annals of Mathematical Statistics vol. 32: 148-170, 1961.

[6] N. Corbett, "Transforming cities : revival in the square," RIBA Enterprises, London2004.

[7] K. Lynch, A theory of good city form. Cambridge, Mass.: MIT Press, 1981.

[8] H. Soltanzadeh, Urban Spaces in the Historical Texture of Iran. Iran: Tehran: Culture research in municipality of Tehran, 1991.

[9] M. Carmona and M. J. Portella, "Capital spaces: designing the new London Square," University College London., London2008.
[10] R. Abouei, "Urban Planning of Isfahan in the Seventeenth Century " PhD, School of Architecture, The University of Sheffield, Sheffield, United Kingdom, 2005.

[11] IMP. (2008, International Affairs Division of Isfahan. Available:

http://isfahan.ir/Index.aspx?tempname=iadim\&lang=3\&sub $=70$

[12] W. Bank. (2002, Country brief of Iran', by Najat Yamouri. Available:

http://web.worldbank.org/WBSITE/EXTERNAL/COUNTRIE S/MENAEXT/IRANEXTN/0,,menuPK:312966 pagePK:141

132 piPK:141107 theSitePK:312943,00.html

[13] K. Karimi and N. Motamed, "The tale of two cities: Urban Planning of the city of Isfahan in the past and present," presented at the 4th International Space syntax Symposium, London, United Kingdom, 2003.

[14] E. Yar-Shater, "Encyclopaedia Iranica Paul," ed. United States Routledge \& Kegan, 2008.

[15] M. S. Habibi, From Precity to City. Tehran: Tehran University Press, 2002.

[16] P. Joshi. (2003, Project for Public Spaces. Available: http://www.pps.org/great_public_spaces//one?public_pl ace_id $=672$

[17] M. Charkhchian and S. A. Daneshpour, "Interaction among different dimensions of responsive public space," Review of Urban \&Regional development studies, vol. 21, 2009.

[18] N. Ardalan and L. Bakhtiar, The sense of unity : the Sufi tradition in Persian architecture. Chicago: University of Chicago Press, 1973.

[19] Lonely-Planet. (2011, Map of Esfahan. Available: http://www.lonelyplanet.com/maps/middle-east/iran/esf ahan/

[20] B2B. (2011, Iranian Historical Photographs: Aerial view from Enghelab (Revolution) Square connecting to 33pol bridge Isfahan Available:

http://www.fouman.com/history/img/Enghelab_Square_ 33pol_Isfahan_Aerial.jpg 
Appendix A. Series pictures taken in order to observe the social behaviour in Naghsh-e-Jahan square and Enghelab Square Enghelab Square: Thursday morning

Enghelab Square: Thursday

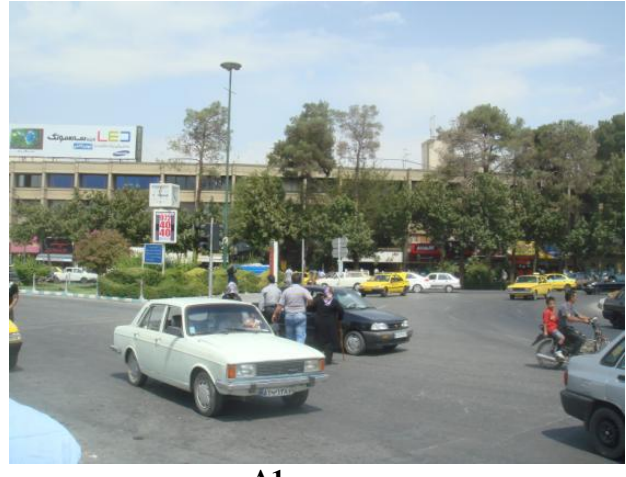

A1

Naghsh-e-Jahan Square: Thursday

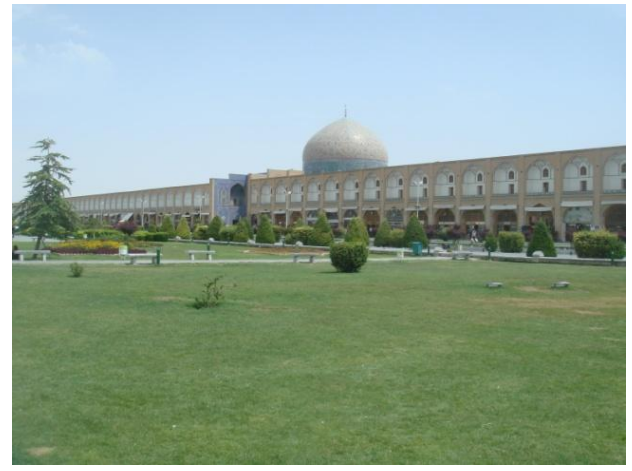

A3
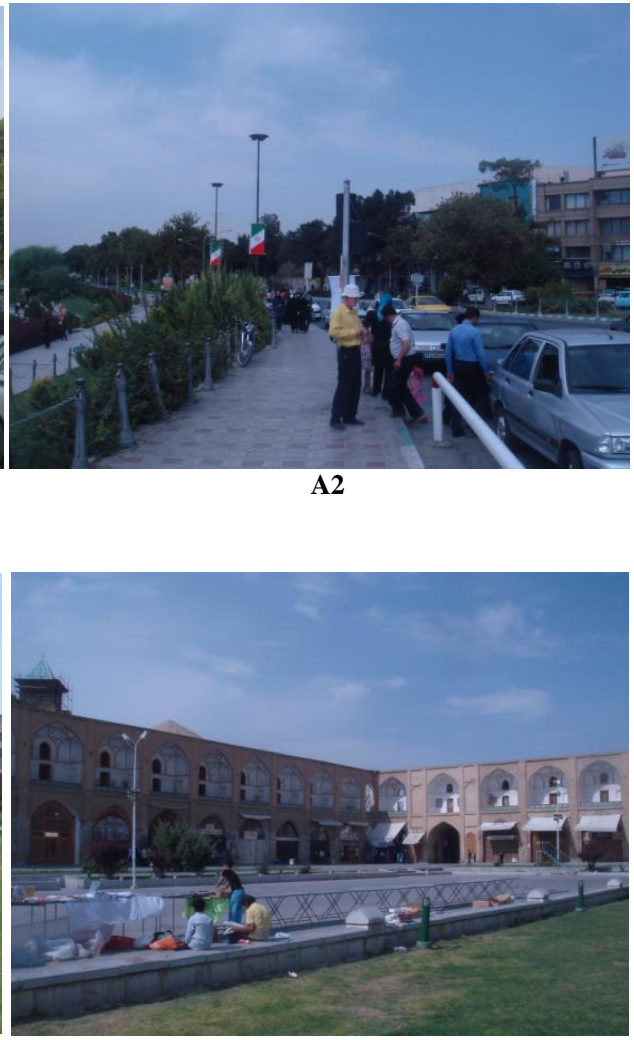

A4 


\section{Appendix B: The Questionnaire}

B1

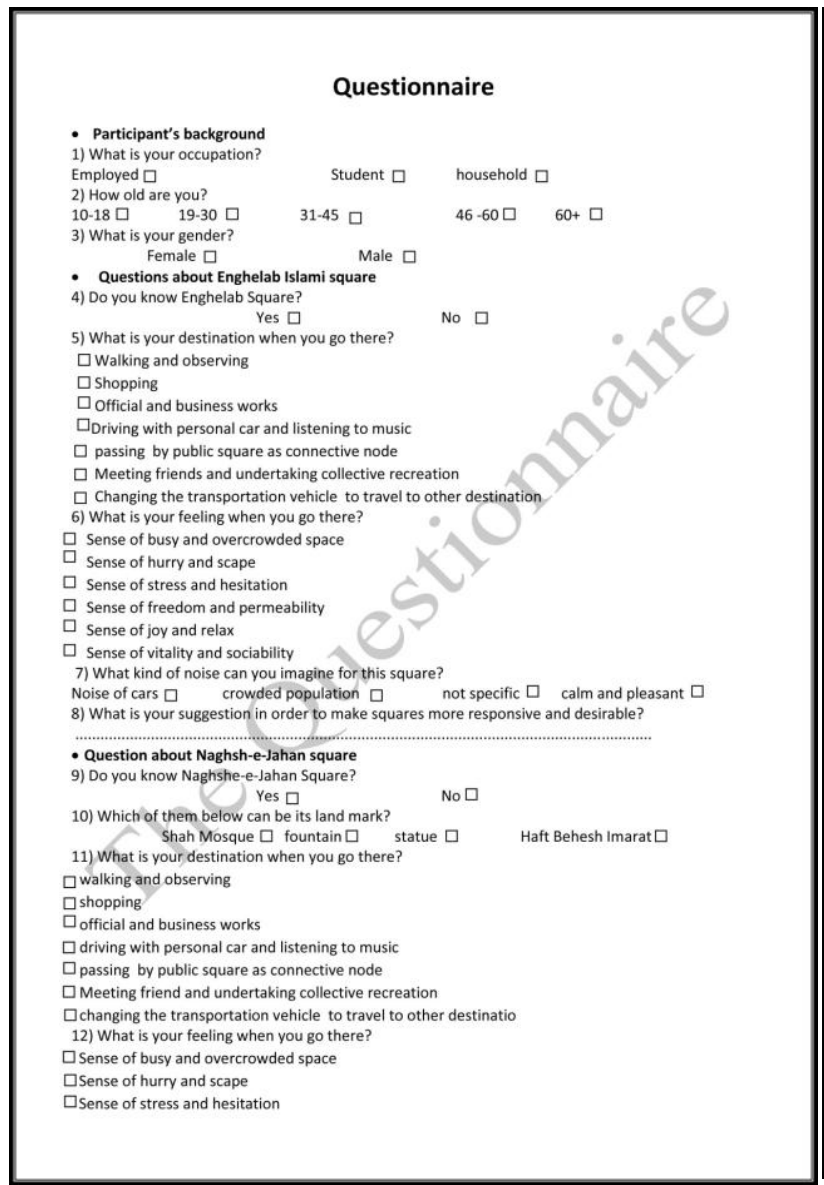

B2 $\square$ Sense of freedom and permeability

$\square$ Sense of joy and relax

$\square$ Sense of vitality and sociability

Swallow Azan (praying voice carriage

14) What is your suggestion in order to make squares more responsive and desirable? 